\title{
PROFIL KOMPETENSI MENYELESAIKAN TES BERFIKIR TINGKAT TINGGI MAHASISWA PROGRAM PENDIDIKAN PROFESI GURU TERINTEGRASI DI PENDIDIKAN SAINS FMIPA UNESA
}

\author{
HasanSubekti \\ Program Studi Pendidikan Sains FMIPA Unesa \\ Jl. Kampus UNESA Ketintang Surabaya 602351 Indonesia \\ Email:hasan sains@yahoo.co.idcom
}

\begin{abstract}
Penerapan IPA perlu dilakukan secara bijaksana untuk menjaga dan memelihara kelestarian lingkungan. Pembelajaran IPA sebaiknya dilaksanakan secara inkuiri (scientific inquiry) untuk menumbuhkan kemampuan berpikir, bekerja, dan bersikap ilmiah serta mengomunikasikannya sebagai aspek penting kecakapan hidup. Oleh karena itu pembelajaran IPA menekankan pada pemberian pengalaman belajar secara langsung melalui penggunaan dan pengembangan keterampilan proses dan sikap ilmiah. Subjek penelitian ini adalah mahasiswa program pendidikan profesi guru terintegrasi berjumlah 32 orang. Sumber data berupa skor siswa hasil analisis tes keterampilan berfikir tingkat tinggi yang dimodifikasi dari Tim USAID Prioritas. Teknik pengambilan data dilakukan oleh peneliti melalui pemberian instrument tes tulis dalam bentukisiankepadamahasiswa, kemudiandikoreksitingkatkebenaranjawabanberdasarkankriteria yang telahditetapkan.Data dianalisissecaradeskriptifkuantitatif.Simpulan dari penelitianiniadalah: Simpulandaripenelitianiniadalah: kompetensimahasiswa $\quad$ PPGT dalammenyelesaikantesberfikirtingkattinggipembelajaransainsberkategoribaik

(denganrerataskor 76,6). Namundemikian, terdapat pula ketercapaian indicator membuatkesimpulan data pengamatandenyutnadi per menit yang menunjukkanskor 56.3dengankategoricukup.Hal

inimenunjukkanbahwaketerampilanberfikirtinggkattingkatmahasiswa

PPGT Unesasecaramayoritassudahbaik, tetapimasihdiperlukanpenguatanpadamateri-materitertentu.
\end{abstract}

Kata kunci :tes, PPGT, keterampilanberfikir, sains

\section{PENDAHULUAN}

Pembelajaran Sains menekankan pada pemberian pengalaman langsung untuk mengembangkan kompetensi agar peserta didik mampu menjelajahi dan memahami alam sekitar secara ilmiah.Menurut Permendikbud 58, 2014: 433) menyatakan IPA diperlukan dalam kehidupan seharihari untuk memenuhi kebutuhan manusia melalui pemecahan masalah-masalah yang dapat diidentifikasikan. Penerapan IPA perlu dilakukan secara bijaksana untuk menjaga dan memelihara kelestarian lingkungan. Pembelajaran IPA sebaiknya dilaksanakan secara inkuiri (scientific inquiry) untuk menumbuhkan kemampuan berpikir, bekerja, dan bersikap ilmiah serta mengomunikasikannya sebagai aspek penting kecakapan hidup. Oleh karena itu pembelajaran IPA menekankan pada pemberian pengalaman belajar secara langsung melalui penggunaan dan pengembangan keterampilan proses dan sikap ilmiah

Pembelajaran Sains diarahkan untuk mencari tahu dan melakukan sehingga 
dapat membantu siswa untuk memperoleh pemahaman yang mendalam tentang alam sekitar. Disebabkan oleh keterkaitan sains dengan kehidupan sekitar dan adanya proses penemuan, maka studi tentang sains melibatkan tiga elemen utama, yaitu: sikap, proses, dan produk. Dengan keterampilan proses sains, diharapkan peserta didik mampu untuk mengembangkan kemampuan berpikir mereka.
Keterampilan
berpikir padadasarnyamerupakanketerampilanmeng gunakanpikiransecara optimal.

Keterampilanberpikirterdiriatasberpikirrasi onal yang diperlukanuntukmemecahkanmasalahsecara ilmiahdanberpikir lateral ataukreatif (Samani, 2007:78).

Keterampilanberpikirmencakupantara lain menggalidanmenemukaninformasi

(information

searching),

kecakapanmengolahinformasidanmengambi lkeputusansecaracerdas (information processing and decision making skill), sertakecakapanmemecahkanmasalahsecaraa rifdankreatif(creative problem solving skill) (Sodiq, 2010:41).MenurutRosana (2012:32) keterampilanberpikirmerupakansalahsatuko mpetensi yang harusdimilikisiswa, olehkarenaituketerampilan-

keterampilanberpikirperludiajarkanpadasis wagunamembekalisiswamampumenghadapi tantangandunianyata yang selaluupdate.

Keterampilanberpikirtingkattinggibuk anmerupakansuatuketerampilan yang dapatberkembangdengansendirinyaseiringd enganperkembanganfisikmanusia.Keteramp ilaniniharusdilatihmelaluipemberian stimulus yang menuntutseseoranguntukberpikirtingkatting gi.Mahasiswasangatmembutuhkanketeramp ilanberpikiruntukmemperolehsertamempros essendiriinformasi-informasi yang merekaperolehdarimanasaja, kapansaja, danpadabidangilmuapasaja.

Sesuaidenganbukupedomanrintisan program pendidikan guru terintegrasiberkewenangantambahan (Rustad, 2012: 9) jika guru memilikiperansentraldalam proses pembelajaran di sekolah, mulaidarijenjangpendidikanusiadinisampais ekolahmenengah. Menurutpermendikbud 61 tahun 2014 menyatakahbahwaKompetensipesertadidik yang diperlukanantara lain berpikirkritisdanmembuatkeputusan, memecahkanmasalah yang komplekssecaralintasbidangkeilmuan, berpikirkreatifdankewirausahaan, berkomunikasidanberkolaborasi, menggunakanpengetahuankesempatansecar ainovatif, mengelolakeuangan, kesehatan, dantanggungjawabwarganegara.

Elder (2007: 17) mengungkapkan lima ciri seseorang yang memiliki keterampilan bepikir tingkat tinggi yaitu: a) dapat memunculkan pertanyaan dan masalah yang penting dan merumuskannya dengan jelas dan tepat; b) dapat mengumpulkan dan menilai informasi yang relevan serta menggunakan ide-ide abstrak untuk menafsirkannya secara efektif; c) dapat menyimpulkan dan memberikan solusi yang baik, dan mengujinya berdasarkan kriteria dan standar yang relevan; d) memiliki keterbukaan pemikiran terhadap pemikiran, pengakuan dan nilai lain; e) dapat berkomunikasi secara efektif dengan orang lain untuk memecahkan masalah yang kompleks.

Sebagai calon guru, sudah seharusnya jika mahasiswa program pendidikan profesi guru terintegrasi juga memiliki kemampuan berfikir tingkat tinggi sebagai acuan bagi siswa agar memiliki kemampuan berfikir tingkat tinggi. Selain itu kemampuan berfikirtingkattinggi guru jugadiperlukan agar guru dapatmelatihkankemampuanberfikirtingkatt inggitersebutpadasiswanya. Hal inisejalandenganPermendikbud, 58 tahun 2014:429 yang menyatakanbahwa proses pembelajarandiarahkanuntukmelatihpeserta didikberpikiranalitis

(pengambilankeputusan)

bukanberpikirmekanistis

(rutin) sertamampukerjasamadankolaborasidalam menyelesaikanmasalah

Tesberfikirtingkattinggidalammakala hiniadalahtesberfikirtingkattinggidalamPem belajaranSains.Pengembanganbutir- 
butirTestersebutmengasahkemampuanberfi kirtingkattinggi (higher order thinking skill)analisissepertisolving problems and investigating the natural world.

Secaraumumrumusanmasalahpeneliti aniniadalah:

Bagaimanaprofilkompetensimahasiswa program pendidikanprofesi guru terintegrasidalammenyelesaikantesberfikirti ngkattinggipadapembelajaransains yang terefleksiketercapaianindikator.

Tujuanpenelitianiniadalahmendeskripsikant ingkatketercapaianindikatortesmahasiswaPr ogram PendidikanProfesi Guru Terintegrasi(PPGT)di program studipendidikansains FMIPA Unesadalammenyelesaikantesberfikirtingka ttinggipembelajaransains.

\section{METODE PENELITIAN}

Penelitian ini dirancang secara kualitatif deskriptif dengan pendekatan pospositivistik rasionalistik model grand concept. Penelitian pospositivistik rasionalistik melandaskan pada filsafat rasionalisme dengan karakteristik pencarian makna di balik data. Payung yang berupa grand conceptsdigunakan agar data empirik dapat dimaknai dalam cakupan yang lebih luas dalam penelitian rasionalistik (Muhajir, 2002:79). Grand Concept dalam penelitian ini adalah bagaimanatingkatpenguasaanmahasiswa program pendidikan guru terintegrasidalammenyelesaikantesberfikirti ngkattinggidalampembelajaransains.

Subjekpenelitianiniadalahmahasiswa program pendidikanprofesi guru terintegrasi (PPGT) berjumlah 32 orang.Penelitianinidilaksanakanpada16Mar et $2014 \quad$ Program StudiPendidikanSainsFMIPA

UniversitasNegeri Surabaya.Sumber data berupaskorhasilanalisistesketerampilanberfi kirtingkattinggi.Instrumenyang digunakandimodifikasidaritesketerampilanb erfikirtingkattinggijenjangsekolahdasardans ekolahmenengahyang dikembangkanoleh Tim USAID Prioritas.Teknikpengambilan data dilakukanolehpenelitimelaluipemberianinstr umenteskepadamahasiswa,

kemudiandikoreksitingkatkebenaranjawaba nberdasarkankriteria yang telahditetapkan. Data

dianalisissecaradeskriptifkuantitatifdenganp engkategorianyang disesuaikandenganPermendikbud58 tahun 2014 sepertipadaTabel 1.

Tabel 1.Predikat, NilaidanPengkategorian Data

\begin{tabular}{|c|c|c|c|}
\hline $\begin{array}{l}\text { Pre- } \\
\text { dikat }\end{array}$ & Nilai & Skormaks & Kategori \\
\hline $\mathrm{A}$ & $3,83>x \geq 4,00$ & 100 & \multirow[t]{2}{*}{ SB } \\
\hline A- & $3,50>x \geq 3,83$ & 92 & \\
\hline $\mathrm{B}+$ & $3,17>x \geq 3,50$ & 83 & \multirow[t]{3}{*}{ B } \\
\hline B & $2,83>x \geq 3,17$ & 75 & \\
\hline B- & $2,50>x \geq 2,83$ & 67 & \\
\hline $\mathrm{C}+$ & $2,17>x \geq 2,50$ & 58 & \multirow[t]{3}{*}{$\mathrm{C}$} \\
\hline $\mathrm{C}$ & $1,83>x \geq 2,17$ & 50 & \\
\hline $\mathrm{C}-$ & $1,50>x \geq 1,83$ & 42 & \\
\hline $\mathrm{D}+$ & $1,17>x \geq 1,50$ & 33 & \multirow[t]{2}{*}{$\mathrm{K}$} \\
\hline $\mathrm{D}$ & $1,00>x \geq 1,17$ & 25 & \\
\hline
\end{tabular}

Sumber: Permendikbud58, (2014:470)

\section{HASIL DAN PEMBAHASAN}

Berikutdiuraikanhasilanalisistingkat kompetensimahasiswa Program Pendidikan Guru Terintegrasi. Presentaseketercapaianindikatortersebutdihi tungdenganmembandingkanjumlahskor yang diperolehpadatiapindikatordenganjumlahsk ormaksimaldaritiapindikatordikalikan $100 \%$.

Hasilanalisistingkatketercapaianindikatorad alahsepertipadaTabel2berikutini.

Tabel2. Tingkat ketercapaianIndikatorberfikirkritis

\begin{tabular}{|c|l|c|c|l|}
\hline No. & Indikator & $\sum$ & $\%$ & Kategori \\
\hline 1. & $\begin{array}{l}\text { Menggolongkan } \\
\text { makhluk hidup. }\end{array}$ & 24 & 75.0 & Baik (B) \\
\hline 2. & $\begin{array}{l}\text { Membuathipotesis } \\
\text { berdasarkanpenga } \\
\text { matan. }\end{array}$ & 28 & 87.5 & $\begin{array}{l}\text { SangatBai } \\
\text { k (A-) }\end{array}$ \\
\hline 3. & Menganalisispeng & 25 & 78.1 & Baik (B) \\
\hline
\end{tabular}




\begin{tabular}{|c|c|c|c|c|}
\hline No. & Indikator & $\sum$ & $\%$ & Kategori \\
\hline & $\begin{array}{l}\text { aruhpopulasiterha } \\
\text { dapkebutuhanpan } \\
\text { gandanketersediaa } \\
\text { nlahan. }\end{array}$ & & & \\
\hline 4. & $\begin{array}{l}\text { Mengidentifikasii } \\
\text { nteraksi di } \\
\text { dalamekosistem. }\end{array}$ & 29 & 90.6 & $\begin{array}{l}\text { SangatBai } \\
\text { k (A-) }\end{array}$ \\
\hline 5. & $\begin{array}{l}\text { Meramalkanaplik } \\
\text { asipemuaianzat. }\end{array}$ & 25 & 78.1 & Baik (B) \\
\hline 6. & $\begin{array}{l}\text { Menganalisishasil } \\
\text { pengamatantentan } \\
\text { gkonseptekanan. }\end{array}$ & 28 & 87.5 & $\begin{array}{l}\text { SangatBai } \\
\mathrm{k}(\mathrm{A}-)\end{array}$ \\
\hline 7. & $\begin{array}{l}\text { Memprediksipeng } \\
\text { aruhgaya } \\
\text { Archimedes } \\
\text { padamassabenda. }\end{array}$ & 21 & 65.6 & Baik (B-) \\
\hline 8. & $\begin{array}{l}\text { Mendesain } \\
\text { percobaanTentang } \\
\text { arah gerak benda. }\end{array}$ & 24 & 75.0 & Baik (B) \\
\hline 9. & $\begin{array}{l}\text { Penafsiran Data } \\
\text { perubahan wujud } \\
\text { zat. }\end{array}$ & 23 & 71.9 & Baik (B-) \\
\hline 10 & $\begin{array}{l}\text { Membuat } \\
\text { kesimpulan data } \\
\text { pengamatan } \\
\text { denyut nadi per } \\
\text { menit. }\end{array}$ & 18 & 56.3 & $\begin{array}{l}\text { Cukup } \\
(\mathrm{C}+)\end{array}$ \\
\hline \multicolumn{2}{|c|}{ Rerata } & 25 & 76.6 & Baik \\
\hline
\end{tabular}

Dari analisis data tersebut, hasilanalisisindikator yang berkagorisangatbaik, yaitu:membuathipotesisberdasarkanpengam atan $(87,5)$, mengidentifikasi interaksi di dalam ekosistem (90,6),menganalisishasilpengamatantentang konseptekanan

(87,5).Namundemikainuntukindikatormem buatkesimpulan data pengamatandenyutnadi per menitdengankategoricukup (skor56.3).MengacukePermendikbud 58 tahun 2014 (469)menyatakanbahwaKetuntasanBelajaru ntukpengetahuandanketerampilanditetapkan denganskor minimal 2,0atauhuruf C.

\section{8}

Membiasakanpesertadidikterkait dengan tantangan yang nyata pada abad 21 , yaitu: lebih menekankan pada upaya untuk melatihkan keterampilan berpikir pada siswa. Keterampilan yang dilatihkan sebaiknya sudah menjangkau pada keterampilan berpikir tingkat tinggi (Rosana, 2012:38). Keterampilanketerampilan berpikir tingkat tinggi tersebut di sadari atau tidak setiap hari dilalui oleh manusia baik di rumah, kelas maupun di manapun.Pengembanganberfikirkritisdanbe rfikirkreatiftidakakanterlepasdaripengemba ngankemampuankinerjaotakkiridanotakkan an yang membutuhkanlatihan yang berlanjut yang dapatdilakukanmelaluipembelajaransemuab idangstudi di sekolah. Untukitu, makakemampuanberfikirtingkattinggidapat dilatihdenganmelakukanlatihansecaraberkel anjutan.

\section{KESIMPULAN}

Simpulandaripenelitianiniadalah: kompetensimahasiswa PPGT dalammenyelesaikantesberfikirtingkattinggi pembelajaransainsberkategoribaik(denganre rataskor76,6). Namundemikian, terdapat pula ketercapaianindicator membuatkesimpulan data pengamatandenyutnadi per menit yang menunjukkanskor 56.3dengankategoricukup.Hal inimenunjukkanbahwaketerampilanberfikirt inggkattingkatmahasiswa PPGT Unesasecaramayoritassudahbaik, tetapimasihdiperlukanpenguatanpadamateri -materitertentu. . 


\section{DAFTAR PUSTAKA}

Elder, Linda. 2007. Our Concept of Critical Thinking. Foundation for Critical Thinking.(Online).Diaksespada 11 April 2014 melaluihttp://www.criticalthinking. org.

Muhadjir, Noeng. 2002. Metodologi Penelitian Kualitatif (Edisi IV). Jogjakarta: Rake Sarasin.

PermendikbudNomor $61 \quad$ tahun2014 tentangKurikulum Tingkat SatuanPendidikan

Rosana, D. 2012. "MenggagasPendidikan IPA yang BaikTerkaitEsensial21 $1^{\mathrm{ST}}$ Century Skills". Disampaikanpada Seminar NasionalPendidikan IPA ke IV, Unesa 2012. Surabaya.

Rustad, Supriadi, dkk. 2012. PedomanRintisan Program

PendidikanProfesi Guru TerintegrasiBerkewenanganTamba han (PPGT).DirektoratPendidikdanTen agaKependidikanDirektoratJendera 1PendidikanTinggiKementrianPend idikandanKebudayaan.

Samani. 2007.

MenggagasPendidikanBermakna:

Integrasi Life Skill-KMK-CTLMBS. Surabaya: Surabaya Intelectual Club.

Sodiq, $\quad$ S. 2009.

PengembanganMateriPendidikan

Kecakapan Hidup Pada Buku

Pelajaran Bahasa Indonesia

Dengan Model Pembelajaran

Literasi.Desertasi. Program

Pascasarjana.Program

StudiPendidikanBahasa Dan

SastraUniversitasNegeri Surabaya. 